https://helda.helsinki.fi

\title{
Swallowing difficulty and nutrient intakes among residents in assisted living facilities in Helsinki
}

\section{Lindroos, Eeva K}

2017-07

Lindroos , E K , Jyväkorpi , S, Soini , H , Muurinen , S , Saarela , R K T, Pitkala , K H \& Suominen, M H 2017 , ' Swallowing difficulty and nutrient intakes among residents in assisted living facilities in Helsinki ' , European Geriatric Medicine , vol. 8 , no. 3 , pp. 228-233 . https://doi.org/10.1016/j.eurger.2017.04.006

http://hdl.handle.net/10138/304256

https://doi.org/10.1016/j.eurger.2017.04.006

publishedVersion

Downloaded from Helda, University of Helsinki institutional repository.

This is an electronic reprint of the original article.

This reprint may differ from the original in pagination and typographic detail.

Please cite the original version. 


\title{
Research paper
}

\section{Swallowing difficulty and nutrient intakes among residents in assisted living facilities in Helsinki}

\author{
E. Lindroos ${ }^{\mathrm{a}, \mathrm{b}, *}$, S. Jyväkorpi ${ }^{\mathrm{a}}$, H. Soini ${ }^{\mathrm{c}}$, S. Muurinen ${ }^{\mathrm{a}}$, R.K.T. Saarela ${ }^{\mathrm{d}}$, K.H. Pitkala ${ }^{\mathrm{a}}$, \\ M.H. Suominen ${ }^{\text {a }}$

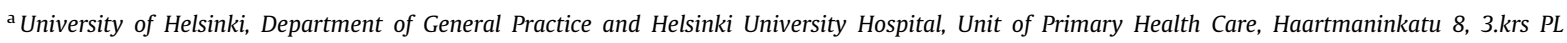 \\ 63 Biomedicum Helsinki, 00014 Helsingin yliopisto, Finland \\ ${ }^{\mathrm{b}}$ Metropolia, University of Applied Sciences, Department of Health Promotion, Mannerheimintie 172, 00300 Helsinki, Finland \\ ${ }^{\mathrm{c}}$ City of Helsinki, Department of Social Services and Health Care, Developmental and Operational Support, Toinen linja 4 A 00530 Helsinki PL 6000,00099 \\ Helsingin kaupunki, Finland \\ ${ }^{\mathrm{d}}$ City of Helsinki, Department of Social Services and Health Care, Oral Health Care, Toinen linja 4 A 00530 Helsinki PL 6000, 00099 Helsingin kaupunki, Finland
}

\section{A R T I C L E I N F O}

\section{Article history:}

Received 23 February 2017

Accepted 14 April 2017

Available online 11 May 2017

\section{Keywords:}

Swallowing difficulty

Dysphagia

Malnutrition

Nutrient deficiency

Morbidity

Mortality

\begin{abstract}
A B S T R A C T
Background: Swallowing difficulty (SWD) commonly occurs and is associated with malnutrition in old age. Less is known of how SWD is associated with various nutrient intakes.

Objectives: To examine how SWD among residents in assisted living facilities.

Materials and methods: In this cross-sectional study, we examined 345 residents in Helsinki in 2007. Detailed energy, protein and nutrient intakes were calculated from 1-day food diaries and compared with the Nordic Nutrition Recommendations (NNRs) as a measure of dietary adequacy. Swallowing was assessed by the closest nurse knowing the resident well. Nutritional status was assessed using the Mini-Nutritional Assessment (MNA).

Results: Of the participants, $14 \%(n=48)$ suffered from SWD, often had prior stroke, increased comorbidities and lower body-mass index. A larger proportion of residents with SWD consumed oral nutritional supplements. The MNA showed that over $52 \%$ of residents with SWD were malnourished, whereas the respective figure was $17 \%$ among residents without SWD. A large proportion of the study population had lower than recommended intakes of energy, protein and micronutrients. However, those with SWD differed significantly from those without only in higher protein and lower zinc and folic acid intakes. Conclusion: Although malnutrition was more common among those with SWD than those without, the daily intakes of energy, protein and micronutrients were similar in these groups, highlighting that the risk of malnutrition and low nutrient intakes commonly occurred in both groups of residents in assisted living facilities.
\end{abstract}

(c) 2017 Elsevier Masson SAS and European Union Geriatric Medicine Society. All rights reserved.

\section{Introduction}

Swallowing difficulty (SWD) or dysphagia is a common health problem in old age [1-3]. SWD complicates eating and may lead to inability to safely swallow liquid or solid foods [4]. SWD may also reduce appetite, due to restrictions in finding adequate foods or in eating safely. This may lead to decrease in food intake, difficulties in food selection and prolonged duration of eating or more dependence on feeding [5,6]. SWD is often associated with malnutrition and risk of malnutrition $[2,7,8]$, which may in turn lead to poor quality of life and increased morbidity $[9,10]$. The

\footnotetext{
* Corresponding author. University of Helsinki, Department of General Practice and Helsinki University Hospital, Unit of Primary Health Care, Finland.

E-mail address: eeva.lindroos@metropolia.fi (E. Lindroos).
}

recent European Union Geriatric Medicine Society (EUGMS) white paper defined SWD as a geriatric syndrome [3].

SWD [3] and malnutrition [11,12] are particularly prevalent in long-term facilities. Among the general population, the prevalence of SWD ranges from $2 \%$ to $16 \%$ [3]; however, in institutional settings, it may become as high as $40 \%$ [3]. Several old-age diseases, such as stroke, Parkinson's disease and dementia may predispose to SWD $[2,3,13,14]$. Malnutrition and SWD frequently coexist and are associated with poor outcomes following stroke $[2,15,16]$, Parkinson's disease [17] and dementia [2]. Complications commonly associated with SWD include malnutrition, dehydration and respiratory infections [3]. SWD is also associated with frailty, multimorbidity, disability and polypharmacy [3]. Although SWD is known to be associated with malnutrition, less is known about how swallowing problems are related to nutrient intakes. Thus, do 
those with SWD have problems in daily energy and nutrient intakes? Is SWD addressed in their nutritional care? The aim of our study was to determine how SWD is associated with resident characteristics, their nutritional status and nutrient intakes in assisted living facilities in Helsinki, Finland.

\section{Materials and methods}

This study was performed in assisted living facilities providing round-the-clock service in Helsinki. These facilities resemble traditional nursing homes, but are more homelike. There are two types of dwellings in assisted living facilities. Those persons having severe cognitive decline live in-group homes, while those cognitively capable may have detached apartments. However, a registered nurse and other caregivers offer round-the-clock care in both settings. In March 2007, the data were collected by registered nurses familiar to the residents. They interviewed, observed and assessed each resident and completed questionnaire. Each nurse was trained thoroughly in performing the assessments and interviews. All participants underwent personal interviews, gathering information with the structured questionnaire on demographic characteristics, functional status and diseases. The participants of the present study are a subsample of a larger study assessing nutritional status and its associated factors in institutional settings [18].

To assess the participants' nutritional status, the nurses were trained using the Mini-Nutritional Assessment (MNA) (revision 2006) [19]. The MNA is a widely used, simple and diagnostically standard screening tool for assessing malnutrition in older persons. A wellvalidated MNA test yields a maximum of 30 points, with $<17$ points indicating malnutrition, 17-23.5 points a risk for malnutrition and $>23.5$ points favourable nutritional status. In addition, each resident's body-mass index (BMI) was calculated by dividing his/her weight in kilograms by the square of the height in metres.
In addition, the nurses gathered the residents' nutrient intakes by completing their 1-day food diaries, under the guidance of a nutritionist (MHS). The participants' energy, protein and nutrient intakes were calculated from these food diaries. The food records were analyzed, using the Aivo program (www.aivo.fi). The nutritionist entered the food diets into the Aivo program under with the supervision of nutrition investigator (MHS). All data were checked and cross-checked.

Age- and sex-specific dietary reference intakes (RIs) [20] were used as reference values for comparing the mean protein, micronutrient, polyunsaturated fatty acids (PUFA) and fibre intakes (Table 1) among the elderly population. Dietary energy was compared with National Nutritional Council's Recommendation [21]. Detailed nutrient intakes were compared with reference intakes (RI) of the Nordic Nutrition Recommendations (NNRs) as a measure of dietary adequacy. For observing inadequate protein intake, the cut-off point per day was $1.2 \mathrm{~g} / \mathrm{kg}$ bodyweight (BW) [22]. We also used the estimated average requirements (ARs) [20] as reference values for inadequate intake of micronutrients, but for comparison of energy, protein, fibre and polyunsaturated fatty acids (PUFA) we only used RIs, because ARs were not available for them [20].

Swallowing problems were charted with a yes/no question evaluated by trained nurses most familiar to the residents. The nurses were instructed to observe how the resident swallowed during eating or feeding. We did not use specific tests for swallowing.

The residents' active medical diagnoses were retrieved from their medical records. We used the Charlson comorbidity index [23] to evaluate the burden of comorbidity for each resident. With this index, the number and seriousness of the residents' comorbid diseases were taken into account to describe their comorbidities.

The Clinical Dementia Rating (CDR) "memory" item was used to evaluate the severity of cognitive impairment. The score in the CDR $(0=$ no memory problems, $0.5=$ possible memory problems, $1=$ mild problems, $2=$ moderate problems or $3=$ severe problems)

Table 1

Characteristics of participants divided according to swallowing difficulty.

\begin{tabular}{|c|c|c|c|}
\hline Variables & $\begin{array}{l}\text { Swallowing difficulty } \\
(n=48)\end{array}$ & $\begin{array}{l}\text { No swallowing difficulty } \\
(n=297)\end{array}$ & $P$-value ${ }^{\mathrm{a}}$ \\
\hline Age, years, mean (SD) & $84.4(6.4)$ & $83.1(7.4)$ & 0.25 \\
\hline Females, \% & 83.3 & 83.5 & 0.98 \\
\hline Memory CDR, \% & & & 0.12 \\
\hline $0-0.5$ & 10.7 & 19.3 & \\
\hline 1 & 8.5 & 15.0 & \\
\hline $2-3$ & 80.9 & 65.7 & \\
\hline Dependent in all $A D L, \%$ & 85.1 & 43.2 & $<0.001$ \\
\hline Charlson, mean (SD) & $2.8(1.6)$ & $2.3(1.4)$ & 0.042 \\
\hline Dementia, \% & 85.4 & 77.4 & 0.21 \\
\hline Parkinson's disease, \% & 2.1 & 6.1 & 0.26 \\
\hline Prior stroke, \% & 37.5 & 21.9 & 0.019 \\
\hline Chronic or recurrent infections, \% & 12.5 & 5.7 & 0.082 \\
\hline Able to walk outside, $\%$ & 27.1 & 43.4 & 0.032 \\
\hline BMI, mean $\mathrm{kg} / \mathrm{m}^{2}(S D)$ & $22.3(4.3)$ & $25.9(4.8)$ & $<0.001$ \\
\hline \multicolumn{4}{|l|}{ MNA } \\
\hline$<17$ & 52.1 & 16.8 & $<0.001$ \\
\hline $17-23.5$ & 41.7 & 67.7 & \\
\hline$>23.5$ & 6.3 & 15.5 & \\
\hline \multicolumn{4}{|l|}{ Symptoms in mouth, \% } \\
\hline Chewing problems & 66.7 & 19.2 & $<0.001$ \\
\hline Dry mouth & 18.8 & 16.8 & 0.74 \\
\hline Eat very little or little, \% & 29.2 & 22.6 & 0.31 \\
\hline Eats fluidly or puree food, \% & 47.9 & 7.7 & $<0.001$ \\
\hline Consumes fluids $<5$ cups per day, $\%$ & 64.6 & 37.0 & $<0.001$ \\
\hline Use of oral nutritional supplements, \% & 12.5 & 3.4 & 0.005 \\
\hline One year mortality, \% & 29.2 & 16.2 & 0.029 \\
\hline
\end{tabular}

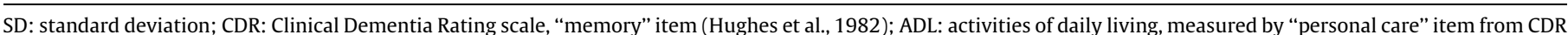

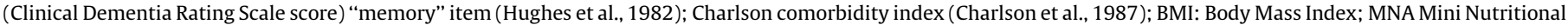
Assessment (Guigoz et al., 1997).

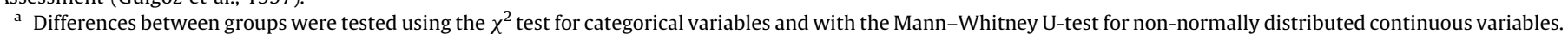


was divided into two groups: those with CDRs $<1$ and those with CDR $>1$ (cognitive impairment). The residents' abilities to manage their activities of daily living (ADL) were evaluated by the nurses according to the item "Personal care" in the CDR [24]. The residents were considered dependent in the ADL if they needed assistance in their personal care (CDR "personal care" at least 2). The nurses provided information on the residents' abilities to walk outside with a yes/no answer.

The nurses evaluated how much of the food offered that the residents consumed during the main meal (1: little, 2: quite little, 3: normal, 4: quite much, 5: much. This was categorized as 1 and 2: little or quite little/3-5: at least a normal portion and the nurses were instructed to compare this with a sample meal. Eating regular snacks and administration of nutritional supplements were charted with yes/no questions. Fluid consumption was retrieved from the MNA questionnaire. Food consistency was inquired, using the following options: 1 : fluid, 2: smooth purée, 3: soft or 4: solid and divided into two groups: 1 : fluid or smooth purée and 2: soft or solid. Oral problems such as dry mouth and chewing problems were assessed by nurses with yes/no questions. Mortality data were retrieved from the central registers.

The data were analysed, using the IBM SPSS (IBM Inc., Armonk, NY, USA) and NCSS (NCSS, LLC, Kaysville, UT, USA) statistical programs. We compared the nutritional status and intake of nutrients between the groups ("no swallowing difficulties" and "swallowing difficulties"), using the $\chi^{2}$ test or Fisher's exact test for categorical variables and the Mann-Whitney U test for continuous variables. Logistic regression with age, gender, comorbidities and nutritional status as covariates was used to determine the independent predictive value of SWD on mortality. $P$ values $<.05$ were considered statistically significant.

\section{Results}

A total of 345 residents living in assisted facilities gave informed consent to this study. The mean age was 83 years and $84 \%$ were females. The nurses stated that $14 \%$ of the participants $(n=48)$ had SWD (Table 1$)$. SWD was associated with higher numbers of comorbidities (mean Charlson comorbidity index 2.8 vs. $2.3, P=0.042$ ). Those residents with SWD were more often diagnosed with prior stroke than those without. There were no differences between the groups in the proportions suffering from dementia or Parkinson's disease. Over half of those elderly having SWD suffered from malnutrition (MNA $<17$ points) $(52 \%$ vs. $17 \%$ ), and only $6.3 \%$ vs. $15.5 \%$ (MNA $>23.5$ points) were well

Table 2

Energy, protein and selected micronutrient intake.

\begin{tabular}{|c|c|c|c|c|}
\hline Mean daily dietary intake & $\begin{array}{l}\text { Swallowing difficulties } \\
(n=48)\end{array}$ & $\begin{array}{l}\text { No swallowing difficulties } \\
(n=297)\end{array}$ & $P$ value $^{\mathrm{a}}$ & $\begin{array}{l}\text { Nordic Nutrition Recommendation (2012) } \\
\text { RI female }(\mathrm{F}) / \text { male }(\mathrm{M}) \\
\text { AR female } / \text { male }^{\mathrm{c}}\end{array}$ \\
\hline Energy kcal (SD) $(n=345)$ & $1689.4(450.9)$ & $1699.2(439.4)$ & 0.97 & F1570/M2070 \\
\hline Among females $(n=288)$ & $1693.6(407.5)$ & $1654.4(403.0)$ & 0.42 & \\
\hline Among males $(n=57)$ & $1668.4(663.0)$ & $1925.7(540.1)$ & 0.14 & $1.2-1.4^{\mathrm{d}}$ \\
\hline Protein, total g (SD) & $60.7(18.0)$ & $61.5(18.8)$ & 0.90 & \\
\hline $\mathrm{g} / \mathrm{BW} \mathrm{kg} / \mathrm{d}$ & $1.1(0.36)$ & $0.97(0.33)$ & 0.005 & \\
\hline Carbohydrate total g (SD) & $228.1(71.0)$ & $223.7(62.4)$ & 0.64 & $\begin{array}{l}<10 \mathrm{E} \% \\
25-35\end{array}$ \\
\hline Sugar & $77.0(35.3)$ & $67.6(30.7)$ & 0.077 & \\
\hline Fibre $\mathrm{g}(\mathrm{SD})$ & $14.2(6.2)$ & $15.2(5.8)$ & 0.15 & \\
\hline Among females & $14.2(6.4)$ & $14.7(5.3)$ & 0.32 & \\
\hline Among males & $14.3(5.1)$ & $17.7(7.6)$ & 0.12 & \\
\hline Fat total, $\mathrm{g}(\mathrm{SD})$ & $56.4(21.4)$ & $58.8(20.6)$ & 0.40 & $\%$ \\
\hline SFA g & $22.9(10.0)$ & $24.4(9.6)$ & 0.28 & $<10 \mathrm{E} \%$ \\
\hline MUFA g & $17.2(7.2)$ & $18.4(7.0)$ & 0.18 & $10-20 \mathrm{E} \%$ \\
\hline PUFA g & $6.7(3.4)$ & $7.2(3.4)$ & 0.26 & $5-10 \mathrm{E} \%$ \\
\hline Vitamin A $\mu g(S D)$ & $597(320)$ & $732(1272)$ & 0.74 & \\
\hline Among females & $601(309)$ & $698(1174)$ & 0.37 & F700/M900 \\
\hline Among males & $579(395)$ & 904 (1687) & 0.52 & $\mathrm{~F} 500 / \mathrm{M} 600^{\mathrm{C}}$ \\
\hline Vitamin $\mathrm{D}^{\mathrm{b}} \mu \mathrm{g}(\mathrm{SD})$ & $16.5(10.5)$ & $13.8(10.1)$ & 0.083 & $\begin{array}{l}20 \\
15^{\mathrm{c}}\end{array}$ \\
\hline Vitamin E mg (SD) & $6.6(2.5)$ & $6.1(2.2)$ & 0.25 & \\
\hline Among females & $6.5(2.1)$ & $6.0(2.2)$ & 0.10 & F8/M10 \\
\hline Among males & $7.0(4.3)$ & $6.8(2.4)$ & 0.85 & $\mathrm{~F} 5 / \mathrm{M}^{\mathrm{c}}$ \\
\hline Vitamin C mg (SD) & $110.9(61.5)$ & $100.5(59.4)$ & 0.22 & $\begin{array}{l}75 \\
50^{\mathrm{C}}\end{array}$ \\
\hline Folic acid $\mu \mathrm{g}(\mathrm{SD})$ & $209.6(82.8)$ & $231.5(108.4)$ & 0.13 & $\begin{array}{l}300 \\
200^{c}\end{array}$ \\
\hline Vitamin B1 mg (SD) & $1.1(0.4)$ & $1.2(0.4)$ & 0.11 & \\
\hline Among females & $1.1(0.4)$ & $1.2(0.4)$ & 0.61 & $\mathrm{~F} 1.0 / \mathrm{M} 1.2$ \\
\hline Among males & $1.0(0.6)$ & $1.4(0.4)$ & 0.028 & F0.9/M1.1 ${ }^{\mathrm{c}}$ \\
\hline Calcium $^{\mathrm{b}} \mathrm{mg}(\mathrm{SD})$ & $1390(568)$ & $1460(608)$ & 0.32 & $\begin{array}{l}800 \\
500^{\mathrm{C}}\end{array}$ \\
\hline Iron mg (SD) & $8.7(4.8)$ & $8.6(2.8)$ & 0.32 & $\begin{array}{l}9 \\
6 / 7^{c}\end{array}$ \\
\hline Zinc mg (SD) & $8.9(3.0)$ & $9.6(2.7)$ & 0.028 & \\
\hline Among females & $8.9(2.9)$ & $9.3(2.5)$ & 0.15 & F7/M9 ${ }^{\mathrm{c}}$ \\
\hline Among males & $8.5(3.5)$ & $10.8(3.0)$ & 0.064 & $\mathrm{~F} 5 / \mathrm{M}^{\mathrm{c}}$ \\
\hline
\end{tabular}

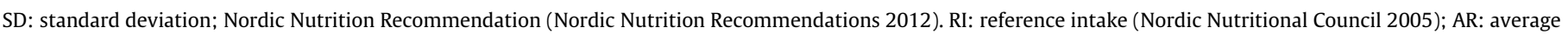

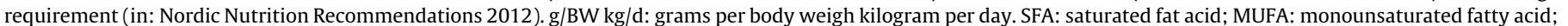
PUFA: polyunsaturated fatty acid.

a Differences between groups were tested with the Mann-Whitney U-test for non-normally distributed continuous variables.

b Includes also supplements.

c AR.

d Bauer et al. 2013. 
nourished. Those with SWD had lower BMIs than those without (22.3 vs. $25.9, P<0.001$ ). Oral nutritional supplements were more often administered to residents with SWD than those without ( $12.5 \%$ vs. $3.4 \% ; P=0.005)$. Those with SWDs consumed less fluids and suffered more often from chewing difficulties than those without. During one-year follow-up period, $29 \%$ of residents with SWDs were deceased whereas the respective figure among those without SWDs was $16 \%(P=0.029)$. In logistic regression analysis adjusting for age, gender, comorbidities and MNA, SWD was no longer significant predictor of mortality (OR: $1.43,95 \%$ CI 0.66 to 3.10 ).

The 1-day food diaries showed that the mean (standard deviation SD) daily energy intake was 1689 (451) kcal in the SWD group and 1699 (439) kcal among participants without SWD. There were no differences between the groups in energy or in most micronutrient intakes. The participants with SWD showed significantly higher intakes of protein than those without $(1.1 \mathrm{~g} /$ BWkg/day vs. $0.97 \mathrm{~g} / \mathrm{BWkg} /$ day; $P=0.005)$. The mean intake of zinc was lower in the SWD group than among those without SWD (Table 2).

Over $40 \%$ of the residents received less energy than recommended [21]. Of those with SWD, 60\% received less protein than recommended [22], whereas the respective figure among those without SWD was $81 \%(P<0.001)$. Although large proportions received micronutrients less than those recommended, there were no differences in intakes of micronutrients between the groups, except for zinc. A larger proportion of those with SWD showed inadequate intake of zinc than those without (31.3\% vs. $18.9 \%$, $P=0.049$ ) (Fig. 1).

Even when the intakes were compared with estimated AR, a large proportion of residents received lower levels than recommended for many micronutrients. A higher proportion of residents with SWD than those without received lower than the AR intakes of folic acid (54.2\% vs. $39.1 \%, P=0.048)$. There were no other differences between the groups in micronutrient intakes compared with the AR (Fig. 2).

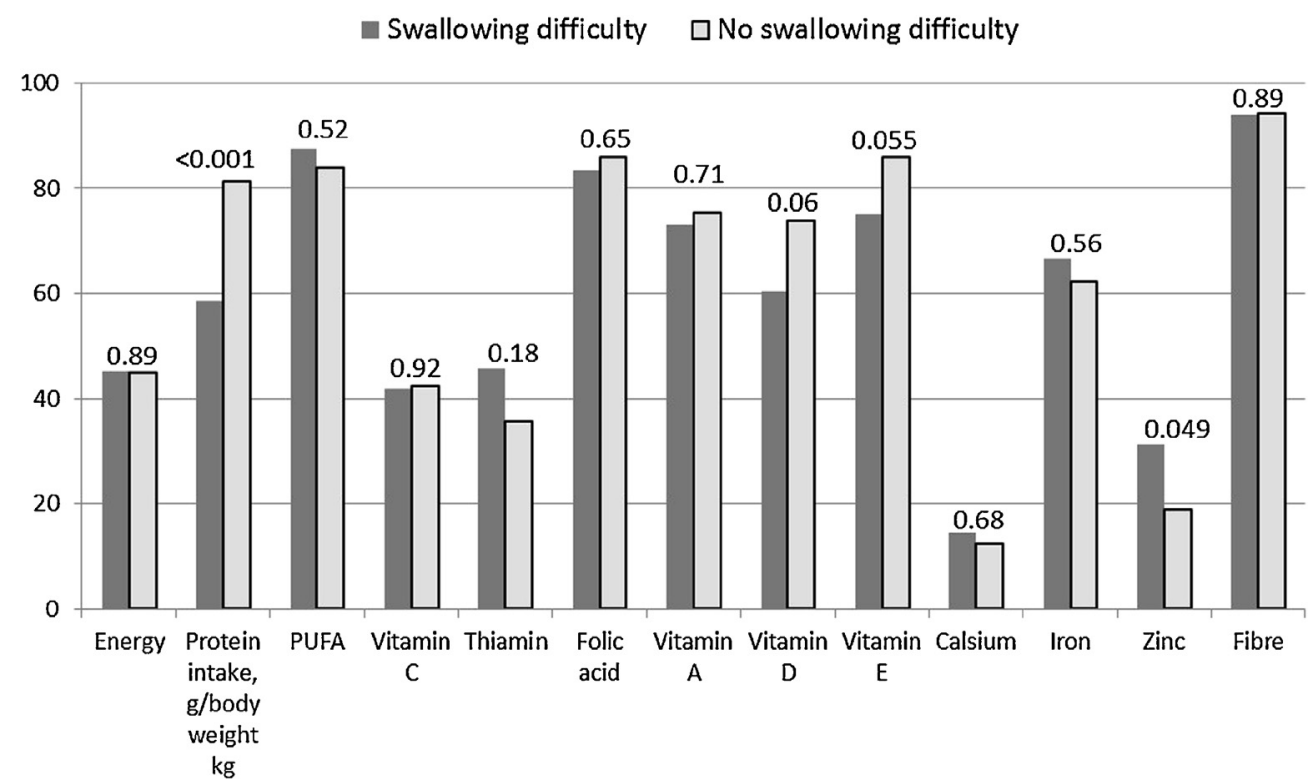

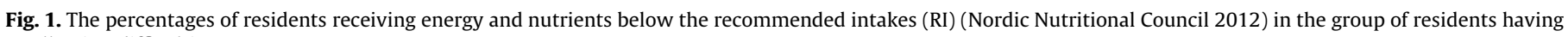
swallowing difficulties or not.

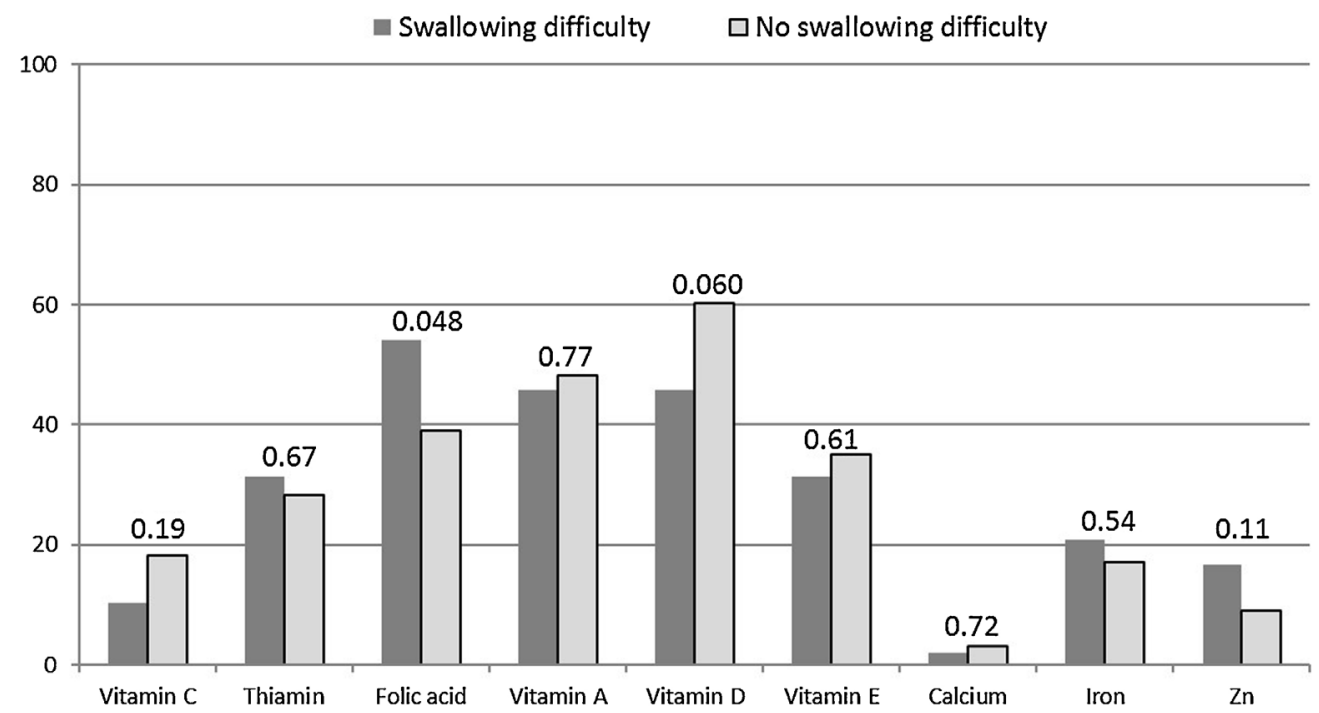

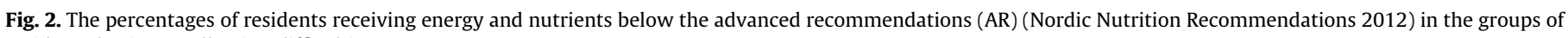
residents having swallowing difficulties or not. 


\section{Discussion}

The nutritional status was poor among those with and without SWD. However, the MNA showed that malnutrition was significantly more common among those having difficulties in swallowing than those without indicating long-term problems in food intakes. Despite the fact that those with SWD showed more prevalent malnutrition and chewing problems and more often consumed fluid/pureed food, there were no differences in daily energy or micronutrient intakes between the groups with and without SWD. In contrast, those with SWD received more protein than those without. However, when the daily intakes were compared with the RIs, a larger proportion of participants with SWD received lower levels of zinc than those without and, furthermore, a smaller proportion received lower levels of folic acid than those recommended in the AR than those without SWD.

The strength of this study lies in the relatively large sample size used for assessing SWD and detailed nutrient intakes among residents of assisted living facilities. Another was the use of detailed food diaries, which have seldom been applied in this context. In addition, the ward nurses received detailed training in performing dietary assessments to ensure correctness of the dietary records. To our knowledge, it is the first large-scale study investigating SWD and its associations with nutrient intake, based on detailed food diaries among older participants under institutional care. One limitation is underestimation of the presence of SWD. Nurses, familiar with the existing swallowing problems of the residents, performed the assessments and also recorded the cases of SWD. In this study, it was not possible to use sophisticated swallowing tests, although this may have compromised the validity of the results. However, these residents with SWD probably represent the proportion having the most obvious SWD, which also should have the most significant nutrition problems. Another limitation of this study may have been the variation in average food intake of participants over longer periods of time, since the 1-day food diary used could not take this into consideration; however, the large sample size lessened this problem. Furthermore, for this reason we used also AR for comparison. Another limitation was also the cross-sectional design, which restricted us to making causal conclusions between SWD and nutrition intake. The participants of this study seem to represent fairly well the population living in assisted living facilities in Helsinki. The mean age, proportion of females, those with SWD, dementia and stroke is similar to the whole population in these facilities [25].

The prevalence of SWD (14\%) in this study was clearly lower than in previous studies that have suggested $32-40 \%$ prevalence rates in nursing homes $[26,27]$. Thus, the point prevalence in our study is truly an underestimate of the problem. Our participants with SWD probably represented the proportion having the most difficult cases of SWD as observed by the nurses. Our findings are also in line with previous studies suggesting the association of malnutrition and swallowing problems $[2,8,28]$.

Our study suggested that those residents with and without SWD did not differ in most micronutrient intakes, while those with SWD received more protein than those without. This may have resulted from nurses focusing more on these residents in respect to their eating than on those without SWD. Thus, the non-existing differences between those with and without SWD may be due to nurses' increased attention in their nutritional care. In general, nurses' awareness of malnutrition in this frail older population is known to be low [29]. The fact that $12.5 \%$ of residents with SWD received nutritional supplements vs. $3.2 \%$ in the other group supports this conclusion. Yet, this $12.5 \%$ is relatively low proportion considering that all of them had SWD. Those with SWD may have suffered from it for lengthy periods, since the proportion suffering from malnutrition was very large. In fact, the nutritional care provided these patients may still have been inadequate and given too late in this frail SWD group. Furthermore, since the nurses probably recognized only the most difficult SWD patients, those with milder SWD may not have received adequate care and prevention in their nutrition.

Most participants in both groups showed poor intakes of energy, PUFAs, folic acid and vitamins A, D and E. Thus, the risks associated with nutrition concerned both those with and without SWD. A larger proportion of participants with SWD received less folic acid than recommended in the AR than participants without SWD. The source of folic acid is mainly green vegetables, which are relatively more difficult to consume in those with SWD than many other foods, unless the vegetables are pureed. Probably, some people with SWD might benefit from folic acid in tablet form. There were also problems in obtaining adequate amounts of zinc among those with SWD. The main sources of zinc for these older residents are beef and poultry, which may be difficult to swallow, thus compromising adequate intake. Zinc could also be acquired from spinach, beans, nuts or wheat germ, but these are less often offered to this generation, which is used to different types of food.

The chewing problems often coincided with SWD among participants with SWD. They also consumed inadequate amounts of fluids. Thus, those with SWD are a special group deserving increased observation. Bartaly et al. [30] showed that having a low intake of more than three nutrients is significantly and independently associated with the presence of frailty.

\section{Conclusion}

Those with SWD are a vulnerable group deserving increased vigilance in nutritional care. Only small proportions of those suffering from SWD are recognized by nurses. Thus, those with less severe SWD may receive inadequate nutritional care at too late a time. Residents with SWD often suffered from malnutrition or were at risk of malnutrition. Although those with SWD received nutritional supplements more often and with larger amounts of protein than those without SWD, their intakes of many micronutrients were compromised. The intakes of micro-and macronutrients were clearly inadequate, irrespective of the presence of SWD.

\section{Ethical Statement}

All the study procedures have been performed according to Helsinki Declaration. The study has been approved by the Helsinki University Central Hospital Ethics Committee.

\section{Author contributions}

Conception and design (EL, SJ, HS, SM, RKTS, KHP, MHS), acquisition of data or analysis and interpretation of data (SJ, KHP, MHS, EL), drafting or critically revising the manuscript for relevant intellectual content (EL, SJ, HS, SM, RKTS, KHP, MHS); approval of the final manuscript (EL, SJ, HS, SM, RKTS, KHP, MHS). KHP had full access to the data used in the study and is responsible for the integrity of the data and the accuracy of data analysis. KHP is the guarantor.

\section{Disclosure of interest}

MSc Eeva Lindroos, Dr Satu Jyväkorpi, Dr Helena Soini, Dr Seija Muurinen, Dr Riitta KT Saarela and Dr Kaisu Pitkala declare that they have no competing interest. 
Dr Merja Suominen reports having lecturing and consulting fees from pharmaceutical and other health care company (Nutricia Medical and Verman).

\section{References}

[1] Barczi SR, Sullivan PA, Robbins J. How should dysphagia care of older adults differ? Establishing optimal practice patterns. Semin Speech Lang 2000;21:347-61.

[2] Sura L, Madhavan A, Carnaby G, Crary MA. Dysphagia in the elderly: management and nutritional considerations. Clin Interv Aging 2012;7:287-98.

[3] Baijens LW, Clavé P, Cras P, Ekberg O, Forster A, Kolb GF, et al. European Society for Swallowing Disorders-European Union Geriatric Medicine Society white paper: oropharyngeal dysphagia as a geriatric syndrome. Clin Interv Aging 2016;7(11):1403-28.

[4] Nogueira DS, Ferreira PL, Reis EA, Lopes IS. Measuring outcomes for dysphagia: validity and reliability of the European Portuguese Eating Assessment Tool (PEAT-10). Dysphagia 2015;30:511-20.

[5] Poels BJJ, Brinkman-Zijlker HG, Dijkstra PU, Postema K. Malnutrition, eating difficulties and feeding dependence in a stroke rehabilitation centre 2006. Disab and Rehabil 2006;28:637-43.

[6] Leow LP, Huckabee ML, Anderson T, Beckert L. The impact of dysphagia on quality of life in ageing and Parkinson's disease as measured by the swallowing quality of life (SWAL-QOL) questionnaire. Dysphagia 2010;25:216-20.

[7] Serra-Prat M, Palomera M, Gomez C, Sar-Shalom D, Saiz A, Montoya JG, et al Oropharyngeal dysphagia as a risk factor for malnutrition and lower respiratory tract infection in independently living older persons: a population-based prospective study. Age Ageing 2012;41:376-81.

[8] Takeuchi K, Aida J, Ito K, Furuta M, Yamashita Y, Osaka K. Nutritional status and dysphagia risk among community-dwelling frail older adults. J Nutr Health Aging 2014;18:352-7.

[9] Norman K, Pichard C, Lochs H, Pirlich M. Prognostic impact of disease-related malnutrition. Clin Nutr 2008:27:5-15.

[10] Ney DM, Weiss JM, Kind AJ, Robbins J. Senescent swallowing: impact, strategies and interventions. Nutr Clin Pract 2009;24:395-413.

[11] Suominen M, Muurinen S, Routasalo P, Soini H, Suur-Uski I, Peiponen A, et al. Malnutrition and associated factors among aged residents in all nursing homes in Helsinki. Eur J Clin Nutr 2005;59:578-83.

[12] Kaiser MJ, Bandinelli S, Lunenfeld B. Frailty and the role of nutrition in older people. A review of the current literature. Acta Biomed 2010;81(Suppl. 1):37-45.

[13] Singh S, Hamdy S. Dysphagia in stroke patients. Postgrad Med J 2006;82: 383-91.

[14] Foley NC, Martin RE, Salter KL, Teasell RW. A review of the relationship between dysphagia and malnutrition following stroke. J Rehabil Med 2009;41:707-13.
[15] Axelsson K, Asplund K, Norberg A, Eriksson S. Eating problems and nutritional status during hospital stay of patients with severe stroke. J Am Diet Assoc 1989;8:1092-6.

[16] Smithard DG, O'Neill PA, Parks C, Morris J. Complications and outcome after acute stroke. Does dysphagia matter? Stroke 1996;27:1200-4.

[17] Walker RW, Dunn JR, Gray WK. Self-reported dysphagia and its correlates within a prevalent population of people with Parkinson's disease. Dysphagia 2011;26:92-6.

[18] Soini H, Suominen MH, Muurinen S, Strandberg TE, Pitkälä KH. Malnutrition according to the mini nutritional assessment in older adults in different settings. J Am Geriatr Soc 2011;59:765-6.

[19] Guigoz Y, Nourhashemi F, Vellas B. The MNA (Mini Nutritional Assessment): update. In: Vellas BJ, Guigoz Y, Garry PJ, Albarede JL, editors. Facts research and intervention in geriatrics: nutrition in the elderly. The Mini Nutritional Assessment (MNA). 3rd ed, Paris: Serdi Publishing Company; 1997. p. 105-12.

[20] Nordic Nutrition Recommendations 2012. Nordic Council of Ministers 2014. doi: 10.6027/Nord 2014-002 Accessed 23.03.14.

[21] National Nutritional Council. Committee: report 2005. Finnish Nutrition Recommendations. Helsinki: Ministry of Agriculture and Forestry; 2005.

[22] Bauer J, Biolo G, Cederholm T, Cesari M, Cruz-Jentoft AJ, Morley JE, et al. Evidence-based recommendations for optimal dietary protein intake in older people: a position paper from the PROT-AGE Study Group. J Am Med Dir Assoc 2013; 14:542-59.

[23] Charlson ME, Pompei P, Ales KL, MacKenzie CR. A new method of classifying prognostic comorbidity in longitudinal studies: development and validation. J Chronic Dis 1987;40:373-83.

[24] Hughes CP, Berg L, Danziger WL, Coben LA, Martin RL. A new clinical scale for the staging of dementia. Br J Psychiatry 1982;140:566-72.

[25] Lindroos E, Saarela RK, Soini H, Muurinen S, Suominen MH, Pitkälä KH. Caregiver-reported swallowing difficulties, malnutrition and mortality among older people in assisted living facilities. J Nutr Health Aging 2014;18: 718-22.

[26] Lin LC, Wu SC, Chen HS, Wang TG, Chen MY. Prevalence of impaired swallowing in institutionalized older people in Taiwan. J Am Geriatr Soc 2002;50: $1118-23$.

[27] Nogueira D, Reis E. Swallowing disorders in nursing home residents: how can the problem be explained? Clin Interv Aging 2013;8:221-7.

[28] Carrión S, Roca M, Costa A, Arreola V, Ortega O, Palomera E, et al. Nutritional status of older patients with oropharyngeal dysphagia in a chronic versus an acute clinical situation. Clin Nutr 2016. http://dx.doi.org/10.1016/j.clnu.2016. 07.009 [pii: S0261-5614(16)30175-3, Epub ahead of print].

[29] Suominen MH, Sandelin E, Soini H, Pitkala KH. How well do nurses recognize malnutrition in elderly patients? Eur J Clin Nutr 2009;63:292-6.

[30] Bartali B, Frongillo EA, Bandinelli S, Lauretani F, Semba RD, Fried LP, et al. Low nutrient intake is an essential component of frailty in older persons. J Gerontol A Biol Sci Med Sci 2006;61:589-93. 